\title{
LEITURA: IMPORTÂNCIA DE DESPERTAR E DESENVOLVER O GOSTO PELO HÁBITO DA LEITURA NOS ANOS INICIAIS DO ENSINO FUNDAMENTAL EM UMA ESCOLA PÚBLICA DE BOA VISTA/RR
}

\author{
Simone Refkalefsky Varela ${ }^{1}$
}

\begin{abstract}
RESUMO: O presente artigo tem como propósito apresentar a pesquisa realizada a partir das experiências vivenciadas em uma escola pública de Boa Vista-RR, onde o ponto norteador foi a Leitura, com foco na importância de despertar e desenvolver o gosto pelo hábito da leitura nos Anos Iniciais do Ensino Fundamental. A elaboração e execução de um projeto de intervenção foi o ponto essencial para o desenvolvimento desse projeto. Nessa perspectiva o trabalho tem como objetivo de analisar e contribuir efetivamente para o desenvolvimento global da escola pública de Boa Vista, no que se refere às estratégias de leitura que favoreçam a formação de leitores durante a realização desse projeto. A metodologia utilizada na pesquisa compreendeu uma abordagem qualitativa, com procedimentos de coleta de dados: as observações, entrevistas e questionários, possibilitando a coleta de dados e a análise dos problemas de maneira mais adequada e relacionada aos objetivos propostos. Possibilitando assim um contato mais direto com os sujeitos: equipe gestora, docentes e discentes. Oportunizando ainda um olhar reflexivo sobre a prática pedagógica na rede pública do Estado de Roraima.
\end{abstract}

Palavras-chave: Leitura; Prática Pedagógica; Escola Pública.

ABSTRACT: This article aims to present the research from the experiences in a public school in Boa Vista, RR, where the point was guiding the reading, focusing on the importance of awakening and developing a taste for the habit of reading in Years initial Elementary School. The design and implementation of an intervention project was the essential point for the development of this project. In this perspective, the study aims to analyze and contribute effectively to the public school in the capital of Boa Vista, in the case of reading strategies that favor the formation of readers during the course of this project. The methodology used in the research included a qualitative approach in data collection procedures: the observations, interviews and questionnaires, providing data collection and analysis of the problem in a more proper and related to the proposed objectives. Thus enabling a more direct contact with the subjects: pedagogical coordinator, teachers and students. Providing opportunities still a reflective look on the practice of public school teachers in the state of Roraima.

Keywords: Reading; Public School; Pedagogical Practice.

\section{INTRODUÇÃO}

Com o surgimento da humanidade, nos primórdios das civilizações na pré-história, o homem buscou se comunicar através de desenhos feitos nas

\footnotetext{
${ }^{1}$ Mestrado em Educação pela Universidad de Alcalá (Espanha). Professora da Rede Pública do Estado de Roraima. Contato: simoneref@yahoo.com.br
} 
paredes das cavernas. Através deste tipo de representação (pintura rupestre), trocavam mensagens, passavam ideias e transmitiam desejos e necessidades. Porém, ainda não era um tipo de escrita, pois não havia organização, nem mesmo padronização das representações gráficas.

Com o passar dos tempos, a escrita se torna então um sistema alfabético ortográfico, onde as letras são representadas pelos seus respectivos sons. Cagliari diz o seguinte sobre a escrita, com o crescimento do sistema de escrita, a quantidade de informações necessárias para que alguém soubesse ler e escrever aumentou significativamente, o que obrigou as pessoas a abandonar o sistema de símbolos para representar e a usar cada vez mais símbolos que representassem sons da fala.

Ao longo do processo de criação da escrita também incluiu a criação de regras de alfabetização, ou seja, regras que permitem ao leitor decifrar o que está escrito e como o sistema de escrita funciona para usá-la apropriadamente. Para Cagliari, o interesse da leitura, para algumas pessoas, estava ligada ao comércio ou até mesmo para ler obras religiosas e para ter informações culturais da época.

A respeito da difícil arte de ler e escrever, Cagliari (2009, p. 156) diz o seguinte:

\footnotetext{
Como se pôde ver nos estudos das letras, as relações entre letras e sons são muito complexas. Isso explica por que decifrar e escrever o nosso sistema de escrita é uma tarefa que exige muito conhecimento. Ficou claro também que as relações entre sons e letras não são exatamente as mesmas relações entre sons e letras [...]. Isso mostra, ainda, que é melhor começar o processo de alfabetização ensinando o aluno a decifrar a escrita e a ler, do que escrever, como faz tradicionalmente o método de cartilhas.
}

Sabe-se que a leitura é uma ferramenta indispensável para a construção de conhecimentos na vida de qualquer ser humano, e o processo de ensinar a ler e escrever nos anos iniciais é uma tarefa complexa, pois na maioria das escolas, quando se inicia o processo de alfabetização, a leitura está na prática de decifrar os sons em letras, dando também mais importância ao escrever do que a leitura, utilizando-se de cartilhas para ensinarem os alunos no início da alfabetização.

Com isso, não vale a pena o professor ficar explicando questões que são muito complexas para que os alunos aprendam a ler e escrever. Cagliari (2009, 
p. 159) mostra um roteiro de ideias gerais para começar uma discussão levando em conta alguns tópicos:

Quando se vai ler

1. Usamos o nome das letras $C$ para saber que som a letra tem: a letra $A$ tem nome de a e o som de "a". A letra "C" tem o nome de "cê" e o som de "çê".

2. Uma letra pode ter mais de um som, representando sons diferentes. A classe vai aprender isso aos poucos. Por enquanto, é só não estranhar se isso acontecer.

3. A letra "A" também tem o som de "ã".

4. A letra "C" tem o som de "cê" somente quando vier antes das letras I e E. Nos demais casos (diante de $A, O, U, R$, L ou de qualquer outra consoante), terá o som de "kê".

Quando se vai escrever

1. Em primeiro lugar, é preciso descobrir a palavra, isolando-a da frase.

2. Depois, é preciso saber a ordem das sílabas na palavra.

3. Checar o que escreveu com a forma gráfica das palavras de acordo com o estabelecido pela ortografia, ou seja, aprender a ter dúvidas ortográficas inteligentes.

4. Resolver as dúvidas ortográficas, perguntando a quem sabe ou olhando no dicionário.

As ideias propostas por Cagliari podem ajudar tanto o docente em sua prática de alfabetização, como também ajudar os alunos a escreverem palavras ou pequenas frases, e até mesmo lerem, claro que com um pouco de dificuldade, mas com o tempo o próprio aluno irá perceber esse processo e estará se aperfeiçoando e aprendendo a respeito da escrita e da leitura.

Para que ocorra um aprendizado significativo da leitura, é preciso que o professor compreenda o sentido amplo de leitura, não é recomendável trabalhar o desenvolvimento da leitura por meio da decodificação, é significativo oferecer aos discentes oportunidades de leitura, oportunizando procedimentos que venha desperta o gosto pela a leitura.

Segundo Martins (2006, p. 19), a valorização do saber ler e escrever, já que trata de signo arbitrário, não disponível na natureza, criado como instrumento de comunicação, registro das relações humanas, das ações e 
aspirações homens transformado com freqüência em instrumento de poder pelos dominadores, mas poder também vir a ser liberação dos dominadores.

Os desenvolvimentos da leitura se davam pelo o método analítico, ou seja, primeiro se decoravam o alfabeto, depois a soletração das sílabas, por fim, a decodificação de palavras isoladas, é utilizada pelos dominantes como instrumento de alienação dos dominados, não possibilitando aos mesmos a leituras críticas da realidade.

A leitura na escola tem sido fundamentalmente um objeto de ensino. Para que possa constituir também como objeto de aprendizagem, é necessário que faça sentido para o aluno, isto é, as atividades de leitura devem responder seu ponto de vista, os objetivos de realização imediata (BRASIL, 1997, p. 54).

A escola precisa está voltada para as atividades de leitura, proporcionar livros de qualidades para os alunos, ter contato com bons materiais de leitura e que os mesmos se sintam motivados pelo hábito da leitura.

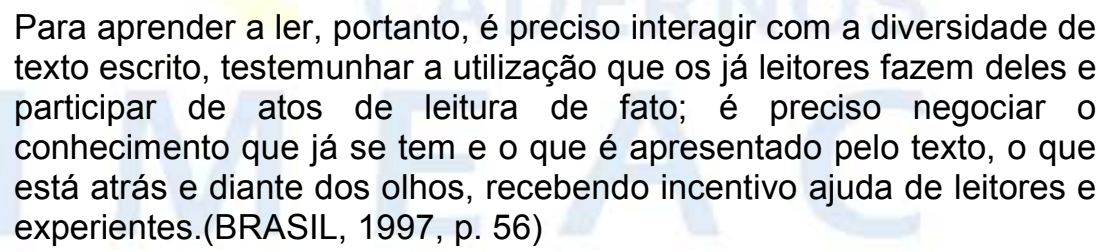

A maioria das escolas não oferece condições de favorecer aos alunos melhor suporte para a leitura, não possibilita condições para esses alunos se tornarem em um bom leitor. Diante desta discussão, cabe às escolas proporcionarem aos discentes, o valor lúdico da leitura de um livro, e que essa descoberta, ajude na leitura ativa e o leve a diversidades de materiais que se encontram a seu alcance.

A respeito desta situação acima comentada, Martins (1994, p. 23) nos traz o seguinte:

\begin{abstract}
A pesar de séculos de civilização, as coisas hoje não são muito diferentes. Muitos educadores não conseguiram superar a prática formalista e mecânica, enquanto para a maioria dos educadores aprender a ler se resume á decoreba de signos lingüísticos, por mais que se doure a pílula com o métodos sofisticado e supostamente desalienantes. Prevalece a pedagogia do sacrifício, do aprender por aprender, sem se colocar o porquê, como e para quê, impossibilitando compreender verdadeiramente a função da leitura, o seu papel na vida do individuo e da sociedade.
\end{abstract}


Esse tipo de concepção tradicional infelizmente, ainda, faz parte da prática de muitos educadores nas salas de aula. Eles transmitem aos educando conteúdos que se resume na decodificação de letras, palavras e depois textos trabalhados a memorização ou decoreba desses, que não tem nenhuma relação com a sua realidade.

A leitura faz parte do processo do ensino e aprendizagem do aluno, mas para que o educando tenha um maior interesse pela leitura, é necessário que o educador se preocupe em fazer com que os alunos sintam prazer pela leitura, precisa ter cuidados ao selecionar textos para seus alunos, esses devem ser atrativos, significativos e de forma intencional, para que a mesma não seja uma ferramenta apenas obrigatória e momentânea. Diante disto, os PCN's, com relação quais são os tipos de leituras, traz:

\footnotetext{
Leitura colaborativa: A leitura em que o professor e alunos realizam paulatinamente, em conjunto; pratica fundamental para explicitação das estratégias e procedimentos que um leitor proficiente utiliza.

Projeto de leitura: trata-se de uma forma de organizar o trabalho que prevê a elaboração de um produto final voltado, necessariamente, para um público externo á sala de aula. As demais modalidades citadas costumam estar articulada em projetos de leitura.

Leitura de escolha pessoal: é a leitura de livre escolha. $O$ aluno seleciona o que quer ler, realiza a leitura individualmente e, depois, apresente sua apreciação para os demais colegas. É uma leitura que possibilita a construção de critérios de seleção e de apreciação estética pessoas.

Leituras permanentes: Os alunos escolhem o que desejam ler, (historias curiosidades científicas, noticias, etc) levam o material para casa por um tempo e se revezam para fazer a leitura em voz alta na classe. Dependendo da extensão dos textos e do que demandam em termos de preparo, a atividade pode se realizar semanalmente, ou quinzenalmente, por um ou mais alunos a cada vez.

Leitura feita pelo professor: $\dot{E}$ a leitura realizada pelos professores. É o caso da leitura compartilhada de livros em capítulos, que possibilita aos alunos o acesso a textos bastante longos (e ás vezes difíceis) que eles nem sempre sejam capazes de ler sozinhos.
}

O universo da leitura envolve o ser humano por todos os lados, as pessoas aprendem a ler antes mesmo de serem alfabetizados, pois desde pequenos, são conduzidos a entender um mundo que se transmite por meio de letras e imagens (rótulos de produtos, propagandas publicitárias, outdoor e outros) estimulando a aprendizagem.

De acordo com a autora Maria Helena Martins (1994), o "ato de ler escrever eram privilégios de alguns na sociedade e da classe dominante, sendo que a classe menos favorecida não tinha esse acesso". 
Segundo Martins (1994, p. 22):

Se conceito de leitura geralmente restrito á decifração da escrita, sua aprendizagem, no entanto, liga-se por tradição do processo de formação global do individuo, a sua capacitação para convivo atuação social, política, econômica e cultural. Saber ler e escrever, já entre os gregos e os romanos, significava possuir as bases de uma educação adequada para a vida, educação essa que visava não só ao desenvolvimento das capacidades intelectuais e espirituais, como das aptidões físicas, possibilidades intelectuais e espirituais, como das aptidões física, possibilitando ao cidadão integram-se efetivamente á sociedades, no caso á classe dos senhores, dos homens livres.

O trabalho com leitura tem como finalidades a formação de leitores competentes e, conseqüentemente, a formação de escritores, pois a possibilidades de produzir textos eficazes tem sua origem na prática de leitura.

Para que ocorra um aprendizado significativo da leitura, é preciso que o professor compreenda o sentido amplo de leitura, não é recomendável trabalhar o desenvolvimento da leitura por meio da decodificação, é significativo oferecer aos discentes oportunidades de leitura, utilizando procedimentos a que venha despertar o gosto pela a leitura.

A valorização do saber ler e escrever, já que trata de signo arbitrário, não disponível na natureza, criado como instrumento de comunicação, registro das relações humanas, das ações e aspirações homens transformado com freqüência em instrumento de poder pelos dominadores, mas pode também vir a ser liberação dos dominador (MARTINS, 2006, p. 19).

Nesse sentido, Cagliari (2008, p. 169) aponta para que: "além de se ter um valor técnico para a alfabetização, a leitura é ainda uma fonte de prazer, de satisfação pessoal, de conquistas, de realização, que serve de grande estímulo e motivação para que a criança goste da escola e de estudar".

\footnotetext{
A leitura na escola tem sido fundamentalmente, um objeto de ensino. Para que possa constituir também objeto de aprendizagem, é necessário que faça sentido para o aluno, isto é, a atividades de leitura devem responder seu ponto de vista, a objetivos de realização imediata. (BRASIL, 1997, p. 54).
}

Para tanto, faz-se necessário acrescentar nos objetos de aprendizagem de leitura do aluno, modalidades de leitura que possam vir a ajudar o educando a ampliar seus conhecimentos através do envolvimento e 
estímulos com textos que partam de sua própria realidade social, textos que sejam significativos e que são utilizados no cotidiano.

Em algumas escolas, quando se aprende a ler, os alunos são forçados a um tipo de leitura mecânica e exaustiva, textos sem sentidos, deixando-os desinteressado pela leitura, lêem sem um direcionamento próprio para o sentido da ação, querem apenas que leiam e pronto. Será essa a função da escola? Dos professores? Com relação a este aspecto, Cagliari (2008, p. 169) diz o seguinte:

Se frustrarmos as crianças, não Ihes dando essa chance, ou pior ainda, se substituirmos essa leitura gostosa por textos mal escritos, o que vamos esperar delas depois? Que graça tem a escola? Para que serve ler e escrever? Para reproduzir?

O papel da escola é fazer com que os alunos sintam prazer pela leitura, e, que ela não seja apenas obrigatória e momentânea.

É preciso ler para se informar, para participar, para ampliar conhecimentos e alcançar uma compreensão melhor da realidade atual e do mundo. Os PCN's (BRASIL, 1997, p. 57) destacam o seguinte:

A leitura, como prática social, é sempre um meio, nunca o fim. Ler é resposta a um objetivo, a uma necessidade pessoal. Fora da escola, não se lê só para aprender a ler, não se lê de uma única forma, não se decodifica palavra por palavra, não se responde a perguntas de verificação do entendimento preenchendo fichas exaustivas, não se faz desenho sobre o que gostou e raramente se lê em voz alta. Isso não significa que na escola não se possa eventualmente responder a perguntas sobre a leitura. No entanto, uma prática constante de leitura não significa a repetição infindável dessas atividades escolares.

A leitura é um "ato solitário", como bem expresso, declara Maria Helena Martins em seu livro "O que é Leitura". Devemos, através dessa afirmação, passar a fazer uma análise crítica. Será que estamos realmente trabalhando a leitura em nossas escolas dentro deste contexto? Fazendo com que os alunos estejam realmente compreendendo o que é ser um leitor? Por isso que dizemos que investir na formação de leitores, assim como na educação é uma tarefa imprescindível.

É importante que os alunos tenham essa disponibilidade de livros e textos, pois é um incentivo e de certa forma um convite aos alunos para o ato da leitura, melhor ainda quando se trata de diferentes tipos de textos, pois 
dessa maneira eles estão adquirindo conhecimentos em diversas áreas e através da leitura desses textos variados se tornaram cidadãos conscientes de seu papel na sociedade. Segundo os PCN's (1997, p 16):

\begin{abstract}
O domínio da língua tem estreita relação com a possibilidade de plena participação social, pois é por meio dela que o homem se comunica, tem acesso à informação, expressa e defende pontos de vista, partilha ou constrói visões de mundo, produz conhecimento. Assim, um projeto educativo comprometido com a democratização social e cultural atribui à escola a função e a responsabilidade de garantir a todos os seus alunos o acesso aos saberes lingüísticos necessário para o exercício da cidadania, direito inalienável de todos.
\end{abstract}

A iniciação do despertar da leitura começa dentro do próprio lar, junto com a o família, incentivando, apoiando e participando da prática da leitura, dessa maneira a escola vai dar seqüência a este trabalho de uma forma sistemática e intencional, sendo leituras que acontecem tanto dentro como fora da escola, leituras que se concebe de forma diferente, onde "A escola é a extensão da leitura na vida das pessoas. A maioria do que se deve aprender na vida terá de ser conseguida através da leitura fora da escola. A leitura é uma herança maior do que qualquer diploma" (CAGLIARI, 2008, p. 148).

Cabe tanto a escola, como ao professor, desenvolver nos alunos competências e habilidades pelo gosto pela leitura, pois assim, o educando passará a compreender melhor o mundo a que está inserido, e compreendera não somente as tarefas de língua portuguesa como também de outras disciplinas, por isso é que devemos oportunizar práticas de leitura para os alunos desde o início da alfabetização.

De acordo com Ezequiel Silva (2002, p. 21), não se forma leitor com uma ou duas cirandas e nem com meia dúzia de sacolas de livros, se as condições sociais e escolares, subjacentes á leitura, não forem consideradas e transformadas. Em nossa intimidade, todos nós sabemos que, aos nos confrontamos com textos densos e inusitados ou até mesmo textos anteriormente lidos, estamos aprendendo a ler, isto vem demonstrar que o ato de ler, se devidamente enraizada na vida do sujeito, não pode ser saciada nos limites fechados de acervos paternalmente doados ás escolas.

A função do educador não seria precisamente de ensinar a ler, mas de criar condições para o educando realizar a sua própria aprendizagem, 
conforme seus próprios interesses, necessidades, fantasias, segundo as dúvidas e exigências que a realidade lhe apresente. Assim, criar condições de leituras não implica apenas alfabetizar ou propiciar acesso aos livros (MARTINS, 2006, p. 34).

O educador tem que conhecer a realidade em que a escola está inserida para que possa desenvolver sua prática. Precisa criar condições para que os alunos venham a desenvolver o interesse pela leitura e fazer um bom planejamento, sempre buscando criar estratégias de leitura para que os alunos sintam prazer de ler, e não ler por obrigatoriedade.

\section{METODOLOGIA}

Este projeto foi desenvolvido a partir de um diagnóstico situacional aplicado aos professores de uma escola pública do centro da cidade de Boa Vista - Roraima com o apoio da equipe gestora da referida escola.

A metodologia que fundamentou este estudo consiste em uma pesquisa bibliográfica e qualitativa, que possibilitou a compreender as relações da escola pública com a formação continuada de professores, de modo a compreender a relevância da leitura. Os instrumentos utilizados para coleta de dados foram observações, co-participações e entrevistas.

As observações serviram para vivenciar as dificuldades que a escola pública perpassa. De acordo com a autora Martins, "[...] não consiste apenas em ver e ouvir, mas também em examinar fatos ou fenômenos que se deseja estudar" (MARTINS, 2008, p.87).

Severino (2007, p. 125), nos diz o seguinte a respeito de observações: "A Observação é todo procedimento que permite o acesso aos fenômenos estudados. É etapa imprescindível em qualquer tipo ou modalidade de pesquisa".

A co-participação foi efetiva em todas as etapas do estudo, contribuindo e enriquecendo o trabalho bibliográfico e empírico.

As entrevistas serviram para identificar qual é a visão dos professores, da coordenação pedagógica, da gestão, e para concretizar essa visão. Segundo os entrevistados na escola pública, a leitura é indispensável na vida de qualquer ser humano, ou seja, o hábito e o gosto pela leitura é base para 
desenvolver leitores em leitores plenos e assíduos. Segundo a visão de Martins a entrevista é "uma conversação efetuada face a face de maneira metódica e seu objetivo é o de proporcionar ao entrevistador, verbalmente, a informação necessária.” (MARTINS, 2008, p. 86).

O significado também de "entrevista", na visão de Severino (2007, p. 124), ficou assim:

\begin{abstract}
A entrevista é a técnica de coleta de informações sobre um determinado assunto, diretamente solicitadas aos sujeitos pesquisados. Trata-se, portanto, de uma interação entre pesquisador e pesquisado. Muito utilizada nas pesquisas da área das Ciências Humanas. Pesquisador visa apreender o que os sujeitos pensam, sabem, representam, fazem e argumentam.
\end{abstract}

\title{
DISCUSSÃO DOS RESULTADOS
}

Durante a execução do projeto foi percebido que os professores seguem uma rotina diária antes de iniciar as aulas (momento da oração, da música, o calendário, a chamada entre outros).

Quanto às práticas pedagógicas, os professores buscam trabalhar dentro do conteúdo que planejam, porém sem o desenvolvimento necessário dos recursos descriminados no planejamento semanal (bingos de leitura, dominós de sílabas, alfabeto móvel e outros).

Ao perguntar aos professores como está o nível de aprendizagem dos alunos, os mesmos foram unânimes em afirmar que as turmas estão em nível iguais de aprendizagem, com exceção de alguns alunos, afirmando que possuem um plano diferenciado para estes.

Para tentar amenizar essa deficiência, foram realizados vários trabalhos de diferentes estratégias metodológicas a fim de alcançar as diversas formas de conhecimento, com atividades lúdicas e diferenciadas, que pudessem ajudar àqueles que apresentam maior dificuldade com a leitura e incentivar os que demonstram mais facilidade.

Quando os professores passavam atividades em sala de aula, esses explicavam com antecedência para que não ocorresse nenhuma dúvida.

Paralelo ao trabalho do professor titular foi desenvolvido tarefas na qual se apresentava dinâmicas motivadoras e, na maioria eram realizadas em pequenos grupos, com jogos visando à integração dos alunos na sala de aula, 
lembrando que as atividades individuais também foram selecionadas conforme as dificuldades apresentadas pelos alunos.

Quanto ao foco da avaliação da tarefa, observamos que os professores planejaram e direcionaram tarefas voltadas em prol do aluno, onde o professor avaliou de acordo com o desenvolvimento, participação, interesse, motivação, percebendo os pontos negativos, para que assim pudessem ser levantadas possíveis soluções, por isso há a importância de se fazer um diagnóstico da turma, da realidade dos alunos, para até mesmo buscar facilitar a aprendizagem.

Foi realizado um plano integrado numa perspectiva interdisciplinar, sendo assim o conhecimento se tornou melhor para interligar as disciplinas, não havendo espaço para o conhecimento fragmentado, estagnado em si. No momento da execução das atividades, foram organizadas as mesas e cadeiras dos alunos em forma de círculos para melhor integração entre eles, onde foi distribuído crachás no chão com o nome dos alunos, de modo que fossem cantando uma música, o aluno pagava seu nome, tornando uma aula bem participativa.

O presente projeto foi realizado nas séries iniciais do ensino fundamental de uma escola pública do centro de Boa Vista.

\section{CONCLUSÃO}

A abordagem desenvolvida neste artigo analisou os aspectos relativos à leitura em sala de aula nas Séries Iniciais do Ensino Fundamental de uma escola pública em Boa Vista, Roraima.

É procedente destacar que todas as ações pedagógicas contribuíram para o desenvolvimento dos alunos e a motivação e interesse dos professores em elaborar planos de aula integrados que contemplasse a necessidade dos alunos, as diversas áreas do conhecimento, tendo como foco 0 desenvolvimento do hábito pela leitura.

A intenção desse projeto foi contribuir com os educadores no processo de ensino aprendizagem da leitura, com metodologias e estratégias que contribuíssem com o desenvolvimento dos educandos de forma efetiva e com aprimoramento e desenvolvimento de verdadeiros leitores. 
Os impactos ocasionados no período das ações pedagógicas desenvolvidas pelo projeto foram reconhecidos de forma positiva e satisfatória por grande parte comunidade escolar (pais, professores, equipe pedagógica e outros profissionais da educação) envolvidos na participação do projeto.

\section{REFERÊNCIAS BIBLIOGRÁFICAS}

BRASIL. Secretaria de Educação Fundamental. Paramentos Curriculares Nacionais: Língua Portuguesa: Ensino de $1^{\text {a }}$ a $4^{\mathrm{a}}$ série. Brasília, DF: 1997.

CAGLIARI, Luis Carlos. Alfabetização e lingüística. $10^{a}$ ed. São Paulo: Spcione, 2008.

Alfabetizando sem o bá-bé-bi-bó-bu. São Paulo: Spcione, 2009.

MARTINS, Maria Helena. O que é leitura. $19^{a}$ ed. São Paulo: Brasiliense, 1994.

SILVA, Ezequiel Theodoro da. Elementos de Pedagogia da leitura. $3^{a}$ ed. São Paulo: Martins Fontes, 1998.

. O ato de ler: fundamentos psicológicos para uma nova pedagogia da leitura. 9. ed. São Paulo: Cortez, 2002.

SILVA, Jaqueline Luzia da. Letramento: uma prática em busca da (re) leitura do mundo. Rio de Janeiro. Wak, Ed. 2009. 220p:

SEVERINO, Antonio Joaquim. Metodologia do trabalho cientifico. $23^{a}$ ed. São Paulo: Cortez ,2007. 